\title{
Benign Cervical Neoplasm
}

National Cancer Institute

\section{Source}

National Cancer Institute. Benign Cervical Neoplasm. NCI Thesaurus. Code C3607.

A non-metastasizing neoplasm that arises from the cervix. Representative examples

include squamous papilloma, endocervical polyp, and rhabdomyoma. 